\title{
Crop protection, environment, health, and biodiversity: observations and outlook
}

\author{
Michel Treilhou $^{1} \cdot$ Jean-François Chollet ${ }^{2} \cdot$ Michel Couderchet $^{3}$
}

Received: 2 April 2015 / Accepted: 9 April 2015 /Published online: 5 May 2015

(C) Springer-Verlag Berlin Heidelberg 2015

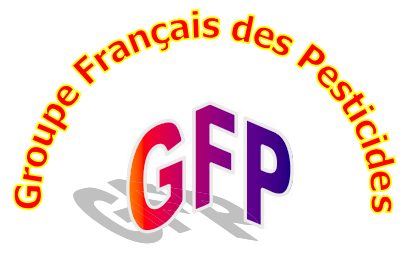

This special issue of Environmental Science and Pollution Research highlights selected papers presented at the 43rd congress organized by the French Group of Pesticide Research ("Groupe Français des Pesticides," GFP) which was held in Albi, from 29 to 31 May 2013, and officially hosted by Champollion University, France. The congress was held in the beautiful settings of the Episcopal city with its Cathedral

Responsible editor: Philippe Garrigues

Michel Treilhou

michel.treilhou@univ-jfc.fr

Jean-François Chollet

jean.franc.chollet@univ-poitiers.fr

Michel Couderchet

michel.couderchet@univ-reims.fr

1 Equipe Venins et Activités Biologiques, EA 4352, Université de Toulouse, CU Champollion, 81012 Albi, France

2 Institut de Chimie des Milieux et Matériaux de Poitiers, Unité Mixte de Recherche CNRS 7285, Université de Poitiers, TSA 51106, 4 rue Michel Brunet, 86073 Poitiers, France

3 Unité de Recherche Vignes et Vin de Champagne, EA 4707, Université de Reims Champagne-Ardenne, BP 1039, 51687 Reims, France and the Toulouse Lautrec museum, recently listed as UNESCO world heritage. Albi is a prefecture city of the Midi-Pyrenees region, one of the most agricultural regions of France.

The GFP met the French scientific community involved in research into phytosanitary compounds. The conferences took place in French and addressed numerous issues dealing with the use of pesticides, their utility to agriculture, and their consequences for the environment and human health. Discussions included their mode of action, analysis and transfer through the environment and along food chains, and finally their elimination.

Occurring annually, this congress is a place of rich exchanges not only between scientists but also with technical institutes, which are becoming increasingly present. These congresses are an opportunity for researchers to present their work and to compare their findings with others in a constructive atmosphere.

Both the contributors and the audience were French researchers from the academic and institutional world, francophone researchers from foreign universities, and researchers from plant protection industries. Representatives from various French agencies, ministries, and agencies in charge of development were one of the audiences: agronomists and technicians also participated in this meeting. Particular encouragement was given to the active participation of young researchers (MSc or $\mathrm{PhD}$ students).

The main objectives of this conference were to review current knowledge of the French-speaking scientific community in all areas concerning pesticides, to feed national debate, to allow the emergence of new paths of research, and to foster collaborations between research organizations, institutions, and industrial environments. 
The exchanges between the research community, institutions, and technicians helped to link scientific knowledge and possible implementation of monitoring or legislation, to identify questions for managers and decision makers, and hence to elicit the emergence of new research orientations.

Facing increasing demands in food production related to the exponential growth of the human population and the current societal expectations for food products with fewer plant protection inputs, the main objective of this congress was to make an inventory of strategies that reconcile these two seemingly contradictory requirements.

The issues of aquatic and environmental contamination were pursued to monitor the dispersal of pesticides in the different compartments, to assess their consequences, and to find remedies.

In order to achieve these various objectives, GFP 2013 was organized in four sessions:

- Phytosanitary compounds: from production to the new forms used for application

- Ecotoxicology: phytosanitary compounds, bees, and other organisms

- Pesticides in water, soil, and air: transfer and effects on ecosystems, remediation

- Pesticides, food, and health

A tribute was paid to professor Michel Schiavon, who died in August 2012. Michel Schiavon was a pioneer in research into the fate of herbicides in soil and the environment. He was part of the team of scientists who founded the GFP in 1977 and chaired it until 2003.

Seven papers were accepted and included in this special issue. They are based on oral presentations at GFP 2013 in Albi highlighting the latest advances in the field of pesticide research with a special focus on the issue of bees.

This key field was chosen by the organizing team according to one of the main research themes conducted in the location hosting the conference, namely the effect of natural products (thymol) used for biocontrol against the bee mite.

The first four articles present ecotoxicology work on aquatic molluscs and crustaceans, and terrestrial organisms such as the bee.

Then, considering the contamination of all environmental compartments of the French West Indies by chlordecone (organochlorine insecticide used in banana plantations), Gaume et al. (2014) studied the effect of the pesticide on Macrobrachium rosenbergii, a giant freshwater prawn of economic importance for Guadeloupe. Using a transcriptomic approach, they showed the induction of genes involved in the defense against oxidative stress in $M$. rosenbergii after exposure to chlordecone.

While chlordecone pollution is particularly well documented and studied, not much is known about metaldehyde, which is also a common pollutant and is perhaps underestimated. Indeed, although the targets of this compound are terrestrial gastropods, it is washed downhill by runoff and, like other pesticides, ends up in the water of estuaries. Moreau et al. (2014) studied the effects of sublethal doses of this compound on a marine mollusc, the oyster. The oyster has been the subject of numerous studies involving phytosanitary compounds, but the work of Moreau et al. (2014) is the first to study metaldehyde. It shows the effects on the health of oysters, especially on the immune system. The authors also show that the genetic heritage of the oysters tested plays a role in explaining the variability of the effects.

The health of pollinators has become a world concern. The multifactorial nature of the collapse in pollinator populations is recognized, and pesticides are known to be not the only elements responsible. Nevertheless, many studies have shown that the honey bee is often a victim of these compounds. In North America, the intensive use of herbicides in corn and soybeans may affect the health of non-target organisms such as bees. Hedrei Helmer et al. (2014) studied the effect of sublethal doses of three herbicides, atrazine, metolachlor, and glyphosate, on lipid peroxidation and diet-derived antioxidants in honey bees. They show that the honey bee carotenoid-retinoid system may be altered by sublethal doses of herbicides.

Natural substances are often presented as alternatives to synthetic pesticides. Essential oils in particular have led to the development of techniques to control the bee mite, Varroa destructor. Thus, different preparations of thymol are permitted and widely used in organic beekeeping.

Taking into account the known effects of phenolic monoterpenes on many insects, Bonnafé et al. (2014) studied the effect of sublethal doses of thymol on phototaxis, olfaction, and memory of bees. The study, which combines behavioral and transcriptomic experiments, showed that thymol may have undesirable effects on bees, even at sublethal doses. This is an opportunity to remember that natural compounds are also bioactive substances and may have undesirable effects on non-target organisms, and the environment, in the same way as synthetic pesticides.

Pesticides can also impact ecosystems in their biodiversity and functioning. Paule et al. (2014) studied the effect of alachlor on phototrophic biofilms. They showed that phototrophic biofilm can be a good bioindicator of river water quality if it is characterized by a multimetric approach 
taking into account its variability, sensitivity to all biotic and abiotic factors, its age, and the duration of exposure to the pesticide.

But the study of the effect of pesticides on the environment and the organisms therein first involves a good assessment of their transfer. The estimation of concentrations in rivers is an important issue to be based on relevant sampling methods. Point sampling programmed during the year does not appear to be very representative of the actual flows of pesticides. Poulier et al. (2014) tested the efficacy of passive samplers such as polar organic chemical integrative samplers (POCIS) placed in the water of two rivers of south western France and showed that this system can detect compounds from pollution peaks (floods). Thus, they were able to reveal, for example, the presence of alachlor, while episodic and less sensitive surveillance campaigns had never spotted it.

The last session of GFP-2013 was devoted to the management of risks to human health. Reducing the use of toxic pesticides and replacing them with compounds less toxic to human health and the environment has become socially, environmentally, and economically vital.

In the last article of this special issue, Mghirbi et al. (2014) evaluated plant protection practices of a small group of winemakers practicing integrated farming in the south of France. This study evaluates the advantage of using toxicity risk indicators as a decision support tool for the different actors of crop management.

Altogether, the articles presented in this special issue scan the different questions dealt with during the GFP2013 congress around the sensitive field of pesticides. We hope that this issue will stimulate interdisciplinary research to open new perspectives and learn more in this exciting field linking crop protection and environmental and human health preservation.

Acknowledgments Authors and reviewers are greatly thanked for their contribution to this issue. The guest editors are also grateful to the "Environmental Science and Pollution Research" editorial board and especially Dr. Philippe Garrigues, editor-in-chief, for the kind invitation to publish this ESPR special issue.

\section{References}

Bonnafé E, Drouard F, Hotier L, Carayon J-L, Marty P, Treilhou M, Armengaud C (2014) Effect of a thymol application on olfactory memory and gene expression levels in the brain of the honeybee Apis mellifera. Environ Sci Pollut Res. doi:10.1007/s11356-0142616-2
Gaume B, Dodet N, Thomé J-P, Lemoine S (2014) Expression of biotransformation and oxidative stress genes in the giant freshwater prawn Macrobrachium rosenbergii exposed to chlordecone. Environ Sci Pollut Res. doi:10.1007/s11356014-3134-y

Hedrei Helmer S, Kerbaol A, Aras P, Jumarie C, Boily M (2014) Effects of realistic doses of atrazine, metolachlor, and glyphosate on lipid peroxidation and diet-derived antioxidants in caged honey bees (Apis mellifera). Environ Sci Pollut Res. doi:10.1007/s11356-0142879-7

Mghirbi O, Ellefi K, Le Grusse P, Mandart E, Fabre J, Ayadi H, Bord J-P (2014) Assessing plant protection practices using pressure indicator and toxicity risk indicators: analysis of the relationship between these indicators for improved risk management, application in viticulture. Environ Sci Pollut Res. doi:10.1007/s11356-014-3736-4

Moreau P, Burgeot T, Renault T (2014) In vivo effects of metaldehyde on Pacific oyster, Crassostrea gigas: comparing hemocyte parameters in two oyster families. Environ Sci Pollut Res. doi:10.1007/s11356014-3162-7

Paule A, Lamy A, Roubeix V, Delmas F, Rols J-L (2014) Influence of the natural growth environment on the sensitivity of phototrophic biofilm to herbicide. Environ Sci Pollut Res. doi:10.1007/s11356-014$3429-\mathrm{Z}$

Poulier G, Lissalde S, Charriau A, Buzier R, Cleries K, Delmas F, Mazzella N, Guibaud G (2014) Estimates of pesticide concentrations and fluxes in two rivers of an extensive French multi-agricultural watershed: application of the passive sampling strategy. Environ Sci Pollut Res. doi:10.1007/s11356014-2814-y

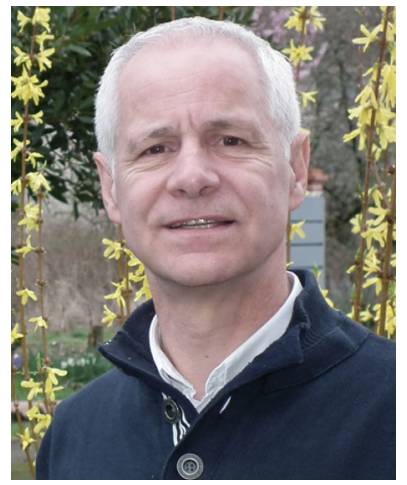

Michel Treilhou He is a professor in the "Venins et Activités Biologiques" team at the University of Albi. Since the late 1980s, his carrier has been devoted to the study of bioactive substances. He has worked on the transfer and the effects of pesticides, drugs, and pollutants both on organisms and the environment. For the last 10 years, his interest in alternatives to pesticides has grown, including the research of natural substances, from plant or animal origin, that can be used in crop biocontrol. His latest works are devoted to natural substances that can, if used without care, have the same side effects as phytosanitary chemicals. For example, his team showed that thymol, extracted from thyme essential oils and used in the fight against the Varroa mite, has side lethal and sublethal effects on bees. Michel Treilhou was the organizer of the 43rd Congress of GFP in Albi. 


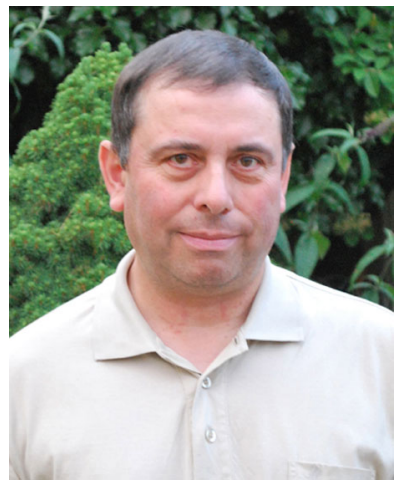

Jean-François Chollet He is a Chargé de Recherches at the IC2MP (Institute of Chemistry of Poitiers: Materials and Natural Resources), a CNRS-Poitiers University joined unit. He works at organic chemistry/plant biology interface, with a special focus on the mobility of xenobiotics and natural products in plants. In particular, he developed original strategies to confer systemicity to non-mobile compounds. He is also interested in the mode of transport of salicylic acid-a stress hormone in plants - by highlighting the intervention of a carrier with an unconventional method. He also imagined a novel use for zeolites, using them to create controlled release environmental-friendly formulations of plant protection products or nutrients. Current research topics are devoted to the development of systemic profungicides, which can then release by enzymatic cleavage the active ingredient in the plant tissues.

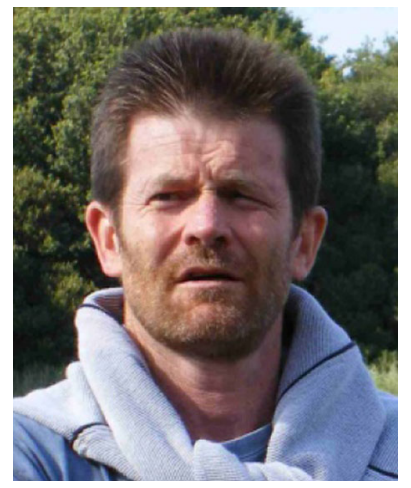

Michel Couderchet He is a professor in the "Unité de Recherche Vigne et Vin de Champagne" at the University of Reims. His work has been devoted to pesticides since the late 1980 s in laboratories in the USA, Germany, and France. His main interest includes the effects of pesticides on the physiology of target and nontarget plants, the behavior, fate, and bioavailability of pesticide in the environment, ecotoxicology of pesticides, and soil and water pollution by these compounds.

He has coauthored over 50 peer-reviewed papers in these domains and participated in over 100 poster or oral presentations in conferences around the world. He has been elected president of the GFP in 2005 and reelected ever since. 